\title{
Ionic Association and Ion-Solvent Interactions. The Conductance of Lithium Bromide in Acetone-Water Mixtures at $15-35^{\circ} \mathrm{C}$
}

\author{
PER BERONIUS
}

Department of Physical Chemistry, University of Umeå, S-901 87 Umeå, Sweden

The electrical conductance of lithium bromide in several aqueous acetone mixtures containing from $5 \times 10^{-3}$ to 20 wt. $\%$ water at 15,25 , and $35^{\circ} \mathrm{C}$ has been studied. The data were treated by means of the conductance equation of Fuoss and Hsia in the form of Fernández-Prini to obtain the ion pair association constant, $K_{\mathrm{A}}$, and the limiting molar conductivity, $\Lambda_{0}$. The minimum center-to-center distance of the ions in the ion pair, derived according to the Gilkerson-Fuoss and Bjerrum theories, and the solvation energies of the free ions relative to the ion pair varies with the composition of the solvent mixture. The heat of activiation, $\Delta H_{0} \neq$, for migration of free ions, obtained from the temperature dependence of $\Lambda_{0}$, increases with increasing proportion of water in the solvent.

The dependence of reaction rate on solvent composition for nucleophilic substitution reactions in mixed solvents may give information concerning preferential solvation of ionic species. In recent investigations ${ }^{1,2}$ of this kind the kinetics of the halogen exchange between lithium bromide and butyl bromide in acetone-water mixtures were investigated over the temperature range $15-35^{\circ} \mathrm{C}$.
Under the prevailing conditions lithium bromide is subject to significant ion pair formation which affects the overall reaction rate because of different reactivities of anionic nucleophile $\left(\mathrm{Br}^{-}\right)$and ion paired nucleophile $\left(\mathrm{Li}+\mathrm{Br}^{-}\right)$. To separate the observed rate constant of the overall exchange reaction into the different rate constants of the two exchange reactions involving free and paired bromide ions, respectively, precise knowledge of the extent of ion pair formation was required. To obtain the information sought the electrical conductance measurements previously performed ${ }^{3}$ at $25^{\circ} \mathrm{C}$ were extended to 15 and $35^{\circ} \mathrm{C}$. The objective of the present paper is to discuss the results of these measurements.

\section{EXPERIMEN'TAL}

Lithium bromide (Merck, suprapur), acetone (Merck, pro analysi), and water were treated as before. ${ }^{3}$ Solutions were prepared by weight. The determinations of densities, $\varrho_{0}$, viscosites, $\eta$, and permittivities, $\varepsilon$, of mixtures of acetone and water have been described. ${ }^{3}$ The results of these determinations are given in Table 1.

Table 1. Properties of acetone-water mixtures at 15 and $35^{\circ} \mathrm{C}$.

\begin{tabular}{lllllll}
\hline $\begin{array}{l}\text { Water conc. } \\
\text { wt-\% }\end{array}$ & $\begin{array}{l}\varrho_{0} \\
\mathrm{~g} \mathrm{~cm}^{-3}\end{array}$ & $\begin{array}{l}\eta \\
\mathrm{cP}\end{array}$ & $\varepsilon$ & $\begin{array}{l}\varrho_{0} \\
\mathrm{~g} \mathrm{~cm}^{-3}\end{array}$ & $\begin{array}{l}\eta \\
\mathrm{cP}\end{array}$ \\
\hline & $15^{\circ} \mathrm{C}$ & & & $35^{\circ} \mathrm{C}$ & & $\varepsilon$ \\
0.005 & 0.79565 & 0.331 & 21.62 & 0.77275 & 0.273 & 19.65 \\
0.10 & 0.79600 & 0.332 & 21.69 & 0.77311 & 0.274 & 19.68 \\
0.30 & 0.79663 & 0.334 & 21.79 & 0.77366 & 0.275 & 19.80 \\
1.00 & 0.79867 & 0.341 & 22.19 & 0.77590 & 0.280 & 20.17 \\
2.00 & 0.80166 & 0.352 & 22.75 & 0.77890 & 0.287 & 20.67 \\
5.00 & 0.81076 & 0.393 & 24.51 & 0.78820 & 0.315 & 22.23 \\
10.0 & 0.82561 & 0.483 & 27.33 & 0.80345 & 0.371 & 24.82 \\
20.0 & 0.85352 & 0.722 & 33.05 & 0.83218 & 0.514 & 30.12 \\
\hline
\end{tabular}

Acta Chem. Scand. A 31 (1977) No. 10 
For each solvent mixture the density, $\varrho$, of the most concentrated solution of lithium bromide was determined. Densities of less concentrated solutions were calculated assuming a linear relationship, ${ }^{3}$

$$
\varrho=\varrho_{0}+A \mathrm{~m}
$$

where $m$ is the molality of lithium bromide. The value of the constant, $A$, was found to be of the order $0.06-0.08 \mathrm{~kg}^{2} \mathrm{~mol}^{-1} \mathrm{dm}^{-8}$.

Electrolytic conductivities of acetone-water mixtures and of lithium bromide solutions were measured by means of a Leeds and Northrup 4666 conductivity bridge. A modified version ${ }^{3}$ of a Daggett-Bair-Kraus conductivity cell,4 provided with a Hawes-Kay salt cup dispensing device ${ }^{5,6}$ was used. A detailed account of the equipment and of the performance of the measurements has been reported. ${ }^{3}$

\section{RESULTS AND CALCULATIONS}

Molar conductivities, $\Lambda$, corrected for the conductivity of the solvent, and the corresponding concentrations, $c$, of lithium bromide in eight different acetone-water mixtures at 15 and $35^{\circ} \mathrm{C}$ are quoted in Tables 2 and 3.

The conductance data were analyzed by means of the equation of Fuoss and Hsia ${ }^{7,8}$ in the form of Fernández-Prini. ${ }^{9}$ For pair-wise associated electrolytes the molar conductivity may be expressed,

$$
\begin{gathered}
\Lambda=\alpha\left[\Lambda_{0}-S(c \alpha)^{1 / 2}+E c \alpha^{10} \log (c \alpha)+J_{1} c \alpha-\right. \\
\left.J_{2}(c \alpha)^{3 / 2}\right]
\end{gathered}
$$

where $\alpha$ is the degree of dissociation of the salt,

\begin{tabular}{|c|c|c|c|c|c|c|c|}
\hline $\begin{array}{l}\text { Run A } \\
c \times 10^{4} \\
M\end{array}$ & $\begin{array}{l}\Lambda \\
\mathrm{cm}^{2} \Omega^{-1} \\
\mathrm{~mol}^{-1}\end{array}$ & $\begin{array}{l}\text { Run B } \\
\underset{M}{M} 10^{4}\end{array}$ & $\begin{array}{l}\Lambda \\
\mathrm{cm}^{2} \Omega^{-1} \\
\mathrm{~mol}^{-1}\end{array}$ & $\begin{array}{l}\text { Run A } \\
c \times 10^{4} \\
\mathbf{M}\end{array}$ & $\begin{array}{l}\Lambda \\
\mathrm{cm}^{2} \Omega^{-1} \\
\mathrm{~mol}^{-1}\end{array}$ & $\begin{array}{l}\text { Run B } \\
c \times 10^{4} \\
\mathbf{M}\end{array}$ & $\begin{array}{l}\Lambda \\
\mathrm{cm}^{2} \Omega^{-1} \\
\mathrm{~mol}^{-1}\end{array}$ \\
\hline \multicolumn{4}{|c|}{0.005 wt. $\%$ water } & \multicolumn{3}{|c|}{2.00 wt. $\%$ water } & \\
\hline 1.1920 & 134.53 & 1.0412 & 137.58 & 2.7461 & 113.09 & 1.0093 & 128.65 \\
\hline 3.1873 & 108.07 & 4.0179 & 101.58 & 5.6086 & 98.086 & 2.4356 & 115.23 \\
\hline 6.5803 & 87.706 & 10.555 & 75.216 & 11.095 & 82.505 & 4.9259 & 100.99 \\
\hline 12.758 & 70.504 & 17.843 & 62.599 & 16.952 & 72.917 & 10.169 & 84.63 \\
\hline 20.443 & 59.588 & 26.954 & 53.787 & 24.057 & 65.265 & 15.648 & 74.715 \\
\hline $\begin{array}{l}28.940 \\
41.452\end{array}$ & $\begin{array}{l}52.364 \\
45.662\end{array}$ & $\begin{array}{l}38.710 \\
40.571\end{array}$ & $\begin{array}{l}46.883 \\
46.052\end{array}$ & 37.924 & 55.899 & $\begin{array}{l}24.641 \\
38.016\end{array}$ & $\begin{array}{l}64.754 \\
55.849\end{array}$ \\
\hline \multicolumn{4}{|c|}{0.10 wt. $\%$ water } & \multicolumn{3}{|c|}{5.00 wt $\%$ water } & \\
\hline 1.2269 & 136.28 & 1.3841 & 133.41 & 1.0834 & 111.48 & 1.1236 & 111.26 \\
\hline 3.4179 & 110.15 & 3.5519 & 108.98 & 2.2247 & 105.88 & 2.4261 & 105.10 \\
\hline 7.0930 & 90.048 & 7.2003 & 89.576 & 4.5525 & 97.970 & 4.6602 & 97.675 \\
\hline 14.938 & 70.732 & 15.008 & 70.629 & 9.6218 & 87.035 & 9.7262 & 86.881 \\
\hline 23.150 & 60.639 & 22.720 & 61.003 & 15.113 & 79.404 & 15.040 & 79.398 \\
\hline 35.782 & 51.669 & 34.160 & 52.542 & 24.306 & 70.926 & 23.626 & 71.385 \\
\hline 52.117 & 44.797 & 42.096 & 48.573 & 37.456 & 63.093 & 36.731 & 63.413 \\
\hline \multicolumn{4}{|c|}{0.30 wt- $\%$ water } & \multicolumn{2}{|c|}{10.0 wt $\%$ water } & & \\
\hline 1.0765 & 138.84 & 1.0031 & 140.36 & 0.98596 & 89.346 & 0.82645 & 89.655 \\
\hline 2.5750 & 118.60 & 2.5991 & 118.46 & 4.7092 & 82.754 & 3.7321 & 84.059 \\
\hline 4.8420 & 101.92 & 4.8536 & 101.87 & 9.6429 & 77.451 & 8.7821 & 78.234 \\
\hline 8.9427 & 85.496 & 9.4336 & 84.102 & 14.678 & 73.532 & 14.224 & 73.736 \\
\hline 16.944 & 69.445 & 17.235 & 69.050 & 23.053 & 68.700 & 23.143 & 68.592 \\
\hline 25.971 & 59.767 & 25.801 & 59.915 & 35.967 & 63.388 & 36.544 & 63.135 \\
\hline 31.177 & 55.925 & $\mathbf{3 7 . 7 3 3}$ & 52.112 & & & & \\
\hline \multicolumn{4}{|c|}{$1.00 \mathrm{wt}-\%$ water } & \multicolumn{3}{|c|}{20.0 wt. $\%$ water } & \\
\hline 3.3508 & 109.99 & 1.1905 & 131.68 & 0.99431 & 65.658 & 1.1065 & 65.539 \\
\hline 6.6958 & 92.805 & 3.0811 & 111.80 & 2.1059 & 64.702 & 2.3999 & 64.515 \\
\hline 13.538 & 75.389 & 6.3078 & 94.188 & 4.2132 & 63.318 & 4.3273 & 63.264 \\
\hline 21.090 & 65.075 & 12.691 & 76.860 & 8.7446 & 61.364 & 8.4286 & 61.453 \\
\hline 29.591 & 57.785 & 19.908 & 66.317 & 13.210 & 59.821 & 13.448 & 59.738 \\
\hline \multirow[t]{2}{*}{43.681} & 50.094 & 28.330 & 58.647 & 21.939 & 57.527 & 26.252 & 56.601 \\
\hline & & 40.927 & 51.275 & $\mathbf{3 3 . 8 6 5}$ & 55.170 & $\mathbf{3 5 . 4 6 7}$ & 54.845 \\
\hline
\end{tabular}
$S$ and $E$ are coefficients ${ }^{10}$ which depend upon

Table 2. Electrical conductance data for lithium bromide in acetone-water mixtures at $15^{\circ} \mathrm{C}$. 
Table 3. Electrical conductance data for lithium bromide in acetone-water mixtures at $35^{\circ} \mathrm{C}$.

\begin{tabular}{|c|c|c|c|c|c|c|c|}
\hline $\begin{array}{l}\text { Run A } \\
c \times 10^{4} \\
M\end{array}$ & $\begin{array}{l}\Lambda \\
\mathrm{cm}^{2} \Omega^{-1} \\
\mathrm{~mol}^{-1}\end{array}$ & $\begin{array}{l}\text { Run B } \\
c \times 10^{4} \\
\mathbf{M}\end{array}$ & $\begin{array}{l}\Lambda \\
\mathrm{cm}^{2} \Omega^{-1} \\
\mathrm{~mol}^{-1}\end{array}$ & $\begin{array}{l}\text { Run A } \\
c \times 10^{4} \\
\mathrm{M}\end{array}$ & $\begin{array}{l}\Lambda \\
\mathrm{cm}^{2} \Omega^{-1} \\
\mathrm{~mol}^{-1}\end{array}$ & $\begin{array}{l}\text { Run B } \\
c \times 10^{4} \\
\mathrm{M}\end{array}$ & $\begin{array}{l}\Lambda \\
\mathrm{cm}^{2} \Omega^{-1} \\
\mathrm{~mol}^{-1}\end{array}$ \\
\hline \multicolumn{4}{|c|}{0.005 wt. $\%$ water } & \multicolumn{4}{|c|}{2.00 wt. $\%$ water } \\
\hline 2.5812 & 126.69 & 2.0369 & 134.79 & 1.0167 & 158.76 & 2.2820 & 142.89 \\
\hline 4.8959 & 105.03 & 3.8790 & 112.79 & 2.3477 & 142.06 & 4.2343 & 127.26 \\
\hline 9.0956 & 85.558 & 6.9233 & 93.899 & 4.6173 & 124.88 & 8.4508 & 107.93 \\
\hline 15.846 & 70.062 & 13.200 & 74.962 & 9.1748 & 105.54 & 14.706 & 92.169 \\
\hline 24.761 & 59.181 & 23.129 & 60.776 & 15.574 & 90.548 & 23.259 & 79.688 \\
\hline 37.415 & 50.393 & $\mathbf{3 6 . 3 1 7}$ & 51.013 & $\begin{array}{l}24.187 \\
36.992\end{array}$ & $\begin{array}{l}78.642 \\
67.950\end{array}$ & 35.632 & 68.870 \\
\hline \multicolumn{8}{|c|}{0.10 wt- $\%$ water } \\
\hline 0.98592 & 161.89 & 1.1803 & 156.77 & \multicolumn{4}{|c|}{5.00 wt- $\%$ water } \\
\hline 1.9739 & 140.31 & 2.6627 & 130.41 & 0.92678 & 145.74 & 0.83810 & 146.26 \\
\hline 3.7329 & 118.95 & 4.7856 & 110.64 & 2.1883 & 136.71 & 2.0229 & 137.71 \\
\hline 8.6198 & 91.747 & 9.3381 & 89.282 & 4.1592 & 126.99 & $\mathbf{3 . 9 3 9 0}$ & 127.90 \\
\hline 15.977 & 73.906 & 16.675 & 72.786 & 8.1880 & 113.96 & 8.0380 & 114.29 \\
\hline 25.181 & 62.437 & 27.454 & 60.423 & 14.588 & 101.13 & 14.296 & 101.58 \\
\hline 39.236 & 52.655 & 40.959 & 51.773 & 23.828 & 89.624 & 23.431 & 90.022 \\
\hline \multicolumn{8}{|c|}{0.30 wt- $\%$ water } \\
\hline 0.84161 & 168.28 & 0.81647 & 168.68 & \multicolumn{4}{|c|}{10.0 wt- $\%$ water } \\
\hline 2.3324 & 139.32 & 2.3303 & 139.32 & 1.0584 & 121.79 & 0.94340 & 122.20 \\
\hline 4.7272 & 116.20 & 4.6339 & 116.79 & 2.3754 & 117.61 & 2.4169 & 117.44 \\
\hline 9.7394 & 93.080 & 8.8837 & 95.876 & 4.4901 & 112.74 & 4.3395 & 113.08 \\
\hline 15.469 & 79.526 & 16.165 & 78.293 & 8.6754 & 105.83 & 8.1853 & 106.44 \\
\hline 25.176 & 66.707 & 26.023 & 65.877 & 15.708 & 97.845 & 14.598 & 98.882 \\
\hline \multirow[t]{2}{*}{39.216} & \multirow[t]{2}{*}{56.446} & 40.258 & 55.871 & 24.793 & 90.719 & 23.486 & 91.575 \\
\hline & & & & 37.012 & 83.919 & 36.684 & 84.053 \\
\hline \multicolumn{8}{|c|}{$1.00 \mathrm{wt}-\%$ water } \\
\hline 1.0460 & 162.09 & 1.1945 & 159.17 & \multicolumn{4}{|c|}{20.0 wt. $\%$ water } \\
\hline 2.4568 & 140.61 & 2.5975 & 139.12 & 0.90058 & 96.052 & 0.86462 & 96.134 \\
\hline 4.1008 & 125.49 & 4.7345 & 121.18 & 2.1879 & 94.269 & 2.0497 & 94.481 \\
\hline 7.9431 & 105.29 & 8.8696 & 101.94 & 4.2901 & 92.239 & 3.9714 & 92.535 \\
\hline 14.124 & 88.147 & 15.531 & 85.455 & 8.3246 & $\mathbf{8 9 . 3 3 5}$ & 7.7610 & 89.746 \\
\hline 22.130 & $\mathbf{7 5 . 7 4 3}$ & 24.411 & 73.190 & 14.899 & 85.952 & 13.650 & 86.556 \\
\hline \multirow[t]{2}{*}{$\mathbf{3 4 . 3 8 8}$} & 64.666 & $\mathbf{3 6 . 5 7 8}$ & 63.208 & 24.209 & 82.390 & 23.137 & 82.767 \\
\hline & & & & 37.159 & 78.671 & 35.845 & 79.021 \\
\hline
\end{tabular}

$\Lambda_{0}, \eta, \varepsilon$, and the absolute temperature, $T$, while the coefficients ${ }^{\ominus} J_{1}$ and $J_{2}$ depend, in addition, upon the maximum center-to-center distance, $R$, between the ions in the ion pair. ${ }^{11,12}$

The association constant for the equilibrium between free and paired ions is defined by the expression,

$K_{\mathrm{A}}=(1-\alpha) /\left(c \gamma^{2} \alpha^{2}\right)$

where $\gamma$ is the mean molar activity coefficient of free ions, which was calculated using the Debye-Hückel equation,

${ }^{10} \log \gamma=-A(c \alpha)^{1 / 2} /\left[1+B R(c \alpha)^{1 / 2}\right]$

where $A$ and $B$ are functions of $\varepsilon$ and $T$.

Acta Chem. Scand. A 31 (1977) No. 10
Using eqns. $(2-4)$ the values of $\Lambda_{0}$ and $K_{\mathrm{A}}$ which minimize $\sigma(\Lambda)$, the standard deviation between measured and calculated $\Lambda$-values, were determined as a function of the distance parameter, $R$, using a computer program described. ${ }^{13}$ Typical examples of the dependence of $\Lambda_{0}$ and $K_{\mathrm{A}}$ on $R$ are shown in Fig. 1.

In most instances the curve obtained upon plotting $\sigma(\Lambda)$ vs. $R$ was found to exhibit two minima for two quite different values of $R, c f$. Fig. 2.

This behaviour, which is not uncommon as has been recently demonstrated, ${ }^{14}$ indicates that the condition, $\sigma(\Lambda)=$ minimum, is not useful as criterion of "best set" conductance parameters. 

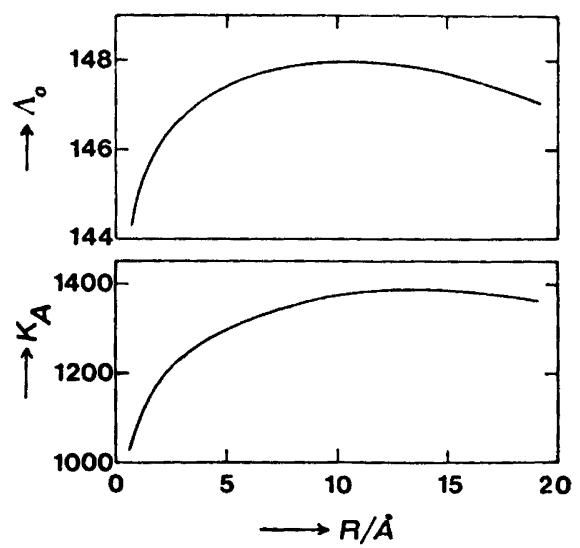

Fig. 1. Dependence of $\Lambda_{0}$ and $K_{\mathrm{A}}$ on the distance parameter, $R$, for $\mathrm{LiBr}$ in aqueous acetone $\left(2\right.$ wt- $\% \mathrm{H}_{2} \mathrm{O}$ ) at $15^{\circ} \mathrm{C}$.
Since there exists at present no method of determining the value of $R$ uniquely, this distance parameter will in the following be set equal to the Bjerrum radius, $q$, which for univalent electrolytes is given by the expression,

$q=e^{2} / 2 \varepsilon k T$

where $e$ is the electronic charge and $k$ is Boltzmann's constant. ${ }^{15}$

A compilation of the values derived for $\Lambda_{0}$, $K_{\mathrm{A}}$, and $\sigma(\Lambda)$ for this choice of $R$ is given in Table 4. The relative standard deviations in $\Lambda_{0}$ and $K_{\mathrm{A}}$ were usually less than 0.2 and $0.5 \%$, respectively. The values of $K_{\mathrm{A}}$ obtained indicate that association to pairs increases with temperature.

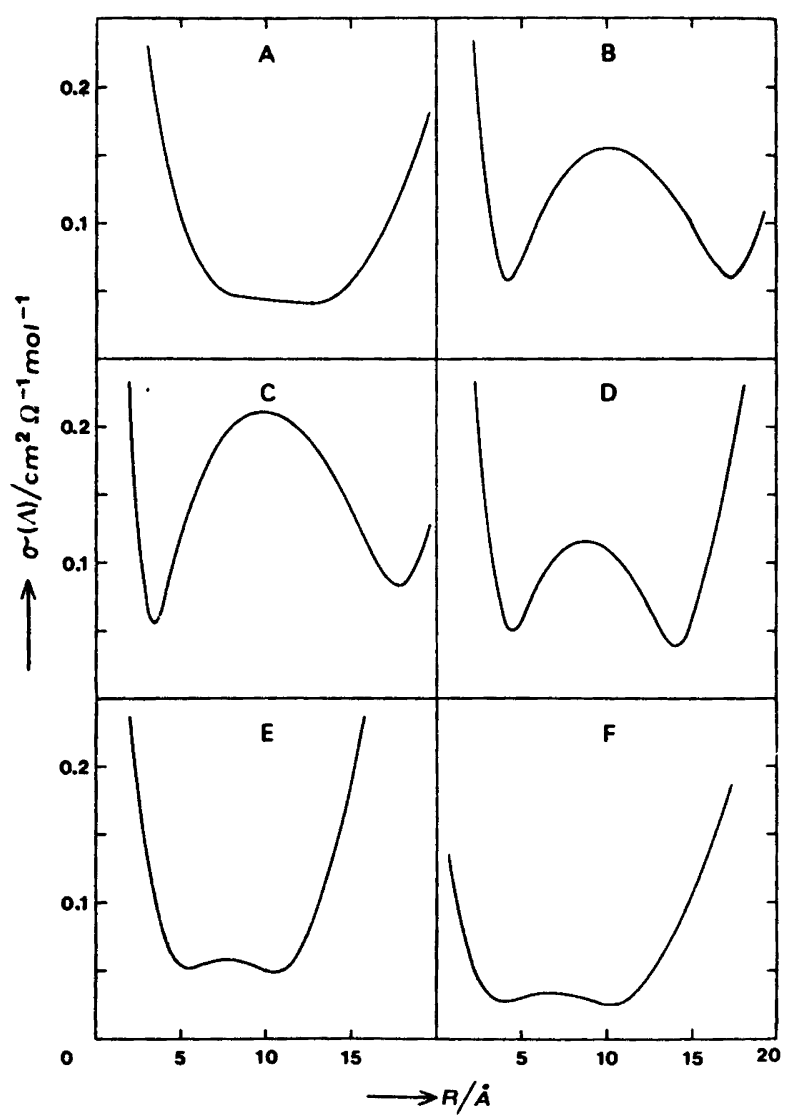

Fig. 2. Dependence of $\sigma(\Lambda)$ on the distance parameter, $R$, for $\mathrm{LiBr}$ in aqueous acetone at $15^{\circ} \mathrm{C}$. The curves $A-F$ refer to solvent mixtures containing $0.3,1,2,5,10$, and 20 wt. $\% \mathrm{H}_{2} \mathrm{O}$, respectively.

Acta Chem. Scand. A 31 (1977) No. 10 
Table 4. Conductance parameters for lithium bromide in acetone-water mixtures.

\begin{tabular}{|c|c|c|c|c|}
\hline $\begin{array}{l}\text { Water conc. } \\
\text { wt. } \%\end{array}$ & $q$ & $\begin{array}{l}\Lambda_{0} \\
\mathrm{~cm}^{2} \Omega^{-1} \mathrm{~mol}^{-1}\end{array}$ & $\underset{\mathbf{M}^{-1}}{K_{\mathbf{A}}}$ & $\begin{array}{l}\sigma(\Lambda) \\
\mathrm{cm}^{2} \Omega^{-1} \mathrm{~mol}^{-1}\end{array}$ \\
\hline \multicolumn{5}{|l|}{$15^{\circ} \mathrm{C}$} \\
\hline 0.005 & 13.41 & 177.0 & 3424 & 0.10 \\
\hline 0.10 & 13.37 & 174.4 & 2813 & 0.07 \\
\hline 0.30 & 13.31 & 171.3 & 2503 & 0.04 \\
\hline 1.00 & 13.07 & 160.4 & 2018 & 0.13 \\
\hline 2.00 & 12.74 & 147.9 & 1385 & 0.19 \\
\hline 5.00 & 11.83 & 120.8 & 516 & 0.08 \\
\hline 10.0 & 10.61 & 93.5 & 171 & 0.05 \\
\hline 20.0 & 8.77 & 67.6 & 42 & 0.03 \\
\hline \multicolumn{5}{|l|}{$25^{\circ} \mathrm{C}$} \\
\hline 0.005 & 13.54 & 194.3 & 4160 & 0.11 \\
\hline 0.10 & 13.47 & 192.7 & 3413 & 0.08 \\
\hline 0.30 & 13.47 & 189.9 & 2839 & 0.06 \\
\hline 1.00 & 13.22 & 179.8 & 2163 & 0.17 \\
\hline 2.00 & 12.79 & 165.7 & 1449 & 0.29 \\
\hline 5.00 & 12.03 & 138.4 & 552 & 0.19 \\
\hline 10.0 & 10.74 & 110.1 & 186 & 0.07 \\
\hline 20.0 & 8.87 & 82.5 & 47 & 0.05 \\
\hline \multicolumn{5}{|l|}{$35^{\circ} \mathrm{C}$} \\
\hline 0.005 & 13.80 & 211.0 & 4513 & 0.10 \\
\hline 0.10 & 13.78 & 211.0 & 3918 & 0.10 \\
\hline 0.30 & $\mathbf{1 3 . 6 9}$ & 206.9 & 3163 & 0.10 \\
\hline 1.00 & 13.44 & 196.4 & 2230 & 0.09 \\
\hline 2.00 & 13.12 & 184.2 & 1534 & 0.19 \\
\hline 5.00 & 12.20 & 157.4 & 603 & 0.10 \\
\hline 10.0 & 10.92 & 128.1 & 205 & 0.04 \\
\hline 20.0 & 9.00 & 98.8 & 52 & 0.02 \\
\hline
\end{tabular}

\section{DISCUSSION}

Taking into account solvent-ion and solvention pair interaction energies, Gilkerson ${ }^{16}$ arrived at the following equation for the ion pair association constant,

$K_{\mathrm{A}}=\left(2 \pi \mu k T / h^{2}\right)^{-3 / 2}\left(g v_{\bar{\sigma}}\right)^{-1} \exp \left(E_{\mathrm{s}} / R T\right)$

$\exp \left(N e^{2} / \varepsilon a R T\right)$

where $R=$ gas constant and $N=$ Avogadro's number. The other symbols are explained in the original paper. ${ }^{16}$

Eqn. (6) contains three adjustable param. eters: the minimum distance, $a$, between the charges in the ion pair; the difference, $E_{\mathrm{s}}$, between solvent-ion and solvent-ion pair interaction energies $\left(E_{\mathrm{s}}=E_{+}+E_{-}-E_{ \pm}\right)$; and $(g v \bar{\sigma})$ which is a function of the free volumes available to the ions and the ion pair.

Later a transformation was made from Gilkerson's free-volume approach ${ }^{16}$ by grafting Acta Chem. Scand. A 31 (1977) No. 10 a specific solvation term ${ }^{17}$ to Fuoss' hard sphere in a continuum model ${ }^{18}$ resulting in the expression:

$K_{\mathrm{A}}=\left(4 \pi N a^{3} / 3000\right) \exp \left(E_{\mathrm{s}} / R T\right) \exp \left(N e^{2} / \varepsilon a R T\right)$

The logarithmic form of this equation indicates that a straight line should be obtained upon plotting $\ln K_{\mathrm{A}}$ vs. $1 / \varepsilon$ at constant temperature provided that $a$ and $E_{\mathrm{s}}$ are independent of the composition of the solvent mixture. However, the graphs shown in Fig. 3 for the systems concerned exhibit significant curvature which increases with decreasing proportion of the protic component.

For a given composition of the solvent mixture ( $a$ and $E_{\mathrm{s}}$ constant) the minimum centerto-center distance between the ions in the ion pair may be calculated from the derivative,

$\frac{d \ln K_{\mathrm{A}}}{d(1 / \varepsilon)}=\frac{N e^{2}}{a R T}$ 


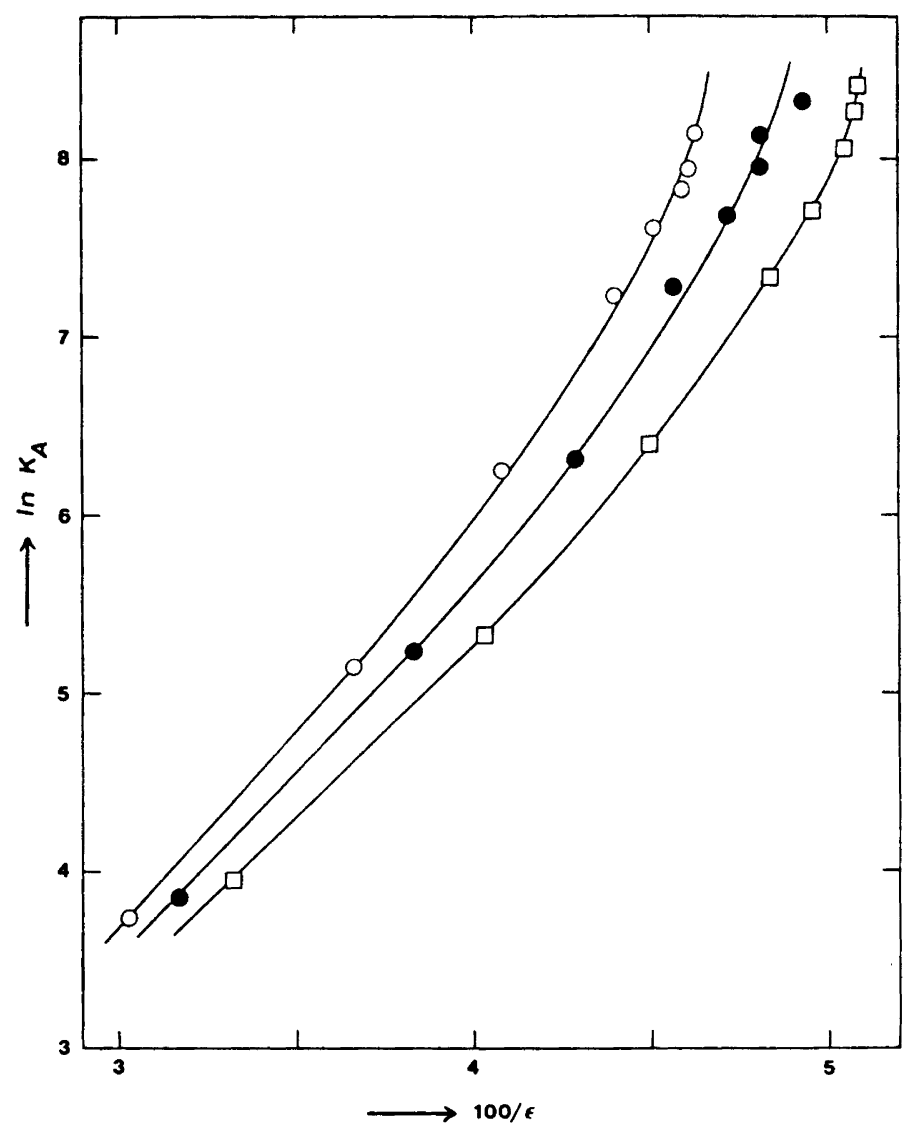

Fig. 3. Graphs of $\ln K_{\mathrm{A}}$ vs. $100 / \varepsilon$ for $\mathrm{LiBr}$ in aqueous acetone at $15^{\circ} \mathrm{C}$ (open circles), $25^{\circ} \mathrm{C}$ (full circles), and $35^{\circ} \mathrm{C}$ (squares).

obtained from eqn. (7). Values of $a$ according to eqn. (7) were calculated from the slopes of the curves in Fig. 3 at four different concentrations of water in the solvent mixture, viz. $0.3,2,5$, and $20 \mathrm{wt} . \%$.

The values of $a$ obtained for the three different temperatures investigated are given in the next to last column of Table 5 in which the corresponding values derived from the Bjerrum equation, ${ }^{15}$

$K_{\mathrm{A}}=\frac{4 \pi N}{1000} \int_{a}^{q} r^{2} \exp \left(\frac{e^{2}}{\varepsilon k T r}\right) \mathrm{d} r$

are included in the second column. The follow ing conclusions may be drawn.

For a given composition of the solvent mixture the minimum center-to-center distance between the ions in the ion pair appears to be independent of temperature. According to the Gilkerson-Fuoss equation, eqn. (7), the average values of $a$ at the three different temperatures investigated amount to $1.1,1.8,2.1$, and $2.7 \AA$ for the solvent mixtures containing $0.3,2,5$, and $20 \mathrm{wt}-\%$ water, respectively. The corresponding average values of $a$ according to Bjerrum's equation, eqn. (9), are 2.1, 2.2, 2.3, and $2.9 \AA$. These values of $a$, being in most instances less than the crystal radii sum of $\mathrm{Li}^{+}$and $\mathrm{Br}^{-}(2.6 \AA)$, obviously underestimate the minimum center-to-center distance between the ions in the ion pair.

The trend of the $a$ values to decrease with decreasing proportions of water in the solvent mixture may possibly be taken as evidence that the character of $\mathrm{Li}^{+} \mathrm{Br}^{-}$as solvent separated

Acta Chem. Scand. A 31 (1977) No. 10 
Table 5. Parameters according to eqns. (7) and (9) for $\mathrm{LiBr}$ in aqueous acetone.

\begin{tabular}{|c|c|c|c|}
\hline $\begin{array}{l}\text { Water conc. } \\
\text { wt. } \%\end{array}$ & $\underset{\AA}{a, ~ e q n . ~(9) ~}$ & $\underset{\AA}{a, \text { eqn. (7) }}$ & $\begin{array}{l}E_{\mathbf{s}} \\
\mathbf{k J} \mathrm{mol}^{-1}\end{array}$ \\
\hline \multicolumn{4}{|l|}{$15^{\circ} \mathrm{C}$} \\
\hline 0.3 & 2.11 & 1.12 & -24.4 \\
\hline 2.0 & 2.22 & 1.79 & -6.9 \\
\hline 5.0 & 2.34 & 2.13 & -2.9 \\
\hline 20.0 & 2.94 & 2.63 & +0.4 \\
\hline \multicolumn{4}{|l|}{$25^{\circ} \mathrm{C}$} \\
\hline 0.3 & 2.12 & 1.20 & -22.3 \\
\hline 2.0 & 2.24 & 1.81 & -7.0 \\
\hline 5.0 & 2.34 & 2.06 & -3.8 \\
\hline 20.0 & 2.85 & 2.71 & +0.7 \\
\hline \multicolumn{4}{|l|}{$35^{\circ} \mathrm{C}$} \\
\hline 0.3 & 2.15 & 1.03 & -32.3 \\
\hline 2.0 & 2.24 & 1.82 & -7.4 \\
\hline 5.0 & 2.36 & 2.11 & -3.6 \\
\hline 20.0 & 2.81 & 2.80 & +1.1 \\
\hline
\end{tabular}

ion pair decreases with decreasing concentration of the protic constituent.

The values of $E_{\mathrm{s}}$ in Table 5 suggest that the difference in solvation energies of the ions and the ion pair decreases with increasing proportions of water in the solvent mixture. For acetone containing $0.3 \mathrm{wt}$-\% water $E_{\mathrm{s}}$ is of the order -20 to $-30 \mathrm{~kJ}$. mol-1. The negative value of $E_{\mathrm{s}}$ indicates that the solvent-ion pair interaction term, $E_{ \pm}$, is greater than the solvention interaction terms, $\left(E_{+}+E_{-}\right)$. For the solvent mixture containing $20 \mathrm{wt}$ \% water $E_{\mathrm{s}}$ is close to zero for all three temperatures studied in. dicating approximately equal solvation energies for the ion pair and the free ions.

On the assumption that the ions migrate through the liquid by successive jumps from one equilibrium position to another and that a characteristic free energy of activation, $\Delta G_{0} \neq$, is required for each jump the limiting molar conductivity of i-ions may be expressed, ${ }^{19}$

$\lambda_{0 i}=\frac{1}{6} \frac{z e F}{h} L_{i}^{2} \exp \left(-\frac{\Delta G_{01} \neq}{R T}\right)$

where $L_{i}$ is the jump distance. The other notations in eqn. (10) have their usual significance.

Differentiation of the logarithmic form of eqn. (10) with respect to temperature at constant pressure and use of the relations, ${ }^{10}$

Acta Chem. Scand. A 31 (1977) No. 10

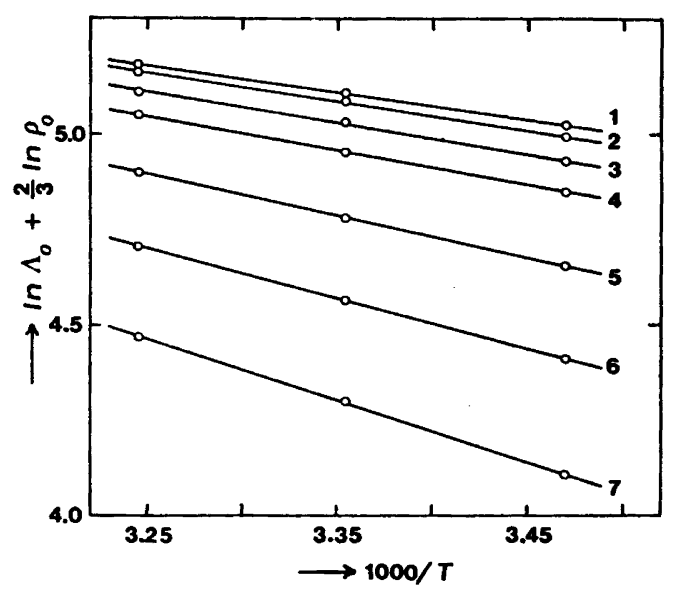

Fig. 4. Graphs according to eqn. (13) for $\mathrm{LiBr}$ in aqueous acetone. The straight lines 1-7 refer to solvent mixtures containing $0.005,0.3$, $1,2,5,10$, and 20 wt- $\% \mathrm{H}_{2} \mathrm{O}$.

$$
\left(\frac{\partial \ln L_{i}}{\partial T}\right)_{P}=\frac{1}{3}\left(\frac{\partial \ln V}{\partial T}\right)_{P}=-\frac{1}{3}\left(\frac{\partial \ln \varrho_{0}}{\partial T}\right)_{P}
$$

results in the following expression,

$$
\Delta H_{0 i} \neq=R T^{2}\left(\frac{\partial \ln \lambda_{0 i}}{\partial T}\right)_{P}+\frac{2}{3} R T^{2}\left(\frac{\partial \ln \varrho_{0}}{\partial T}\right)_{P}
$$

where $\Delta \mathrm{H}_{0 i} \neq$ is the enthalpy change referring to the unit displacement (one jump) of one mol of ions.

Provided that the transport numbers, $t_{i}$ and $t_{j}$, do not change significantly with temperature the integrated form of eqn. (12) may be written,

$\ln \Lambda_{0}+\frac{2}{3} \ln \varrho_{0}=-\frac{\Delta H_{0} \neq}{R T}+B$

where $\Delta H_{0} \neq=t_{i} \Delta H_{0 i} \neq+t_{j} \Delta H_{0 j} \neq$ and $B$ is an integration constant, $c f$. Ref. 20.

Graphs according to eqn. (13) for lithium bromide in several aqueous acetone mixtures are shown in Fig. 4. For the temperature interval studied no temperature dependence of the heat of activation can be detected. Application of eqn. (13) to the experimental data using the method of least squares yields the values of $\Delta H_{0} \neq$ quoted in Table 6.

It is found that $\Delta H_{0} \neq$ increases with increasing proportions of water in the solvent mixture, viz. from $6 \mathrm{~kJ} \mathrm{~mol}^{-1}$ for anhydrous acetone to $13 \mathrm{~kJ} \mathrm{~mol}^{-1}$ for acetone containing $20 \mathrm{wt} \%$ 
Table 6. Dependence of $\Delta H_{0} \neq$ according to eqn. (13) on solvent composition of $\mathrm{LiBr}$ in aqueous acetone.

\begin{tabular}{cc}
\hline $\begin{array}{l}\text { Water conc. } \\
\text { wt.\% }\end{array}$ & $\begin{array}{c}\Delta H_{\mathrm{o}} \neq \\
\mathrm{kJ} \mathrm{mol}^{-1}\end{array}$ \\
\hline 0.005 & 5.8 \\
0.10 & 6.3 \\
0.30 & 6.2 \\
1.00 & 6.8 \\
2.00 & 7.4 \\
5.00 & 9.1 \\
10.0 & 11.0 \\
20.0 & 13.4 \\
\hline
\end{tabular}

15. Bjerrum, N. K. Dan. Vidensk. Selsk., Mat. Fys. Medd. 7 (1926) No. 9.

16. Gilkerson, W. R. J. Chem. Phys. 25 (1956) 1199.

17. Sadek, H. and Fuoss, R. M. J. Am. Chem. Soc. 81 (1959) 4507.

18. Fuoss, R. M. J. Am. Chem. Soc. 80 (1958) 5059 .

19. Brummer, S. B. and Hills, G. J. Trans. Faraday Soc. 57 (1961) 1816.

20. Barthel, J., Wachter, R. and Knerr, M. Electrochim. Acta 16 (1971) 723.

21. Harned, H. S. and Owen, B. B. The Physical Chemistry of Electrolytic Solutions, 3rd Ed., Reinhold, New York 1964, p. 234.

Received June 30, 1977

water. Compare $\Delta H_{0} \neq=15 \mathrm{~kJ} \mathrm{~mol}^{-1}$ for lithium bromide in water at $25^{\circ} \mathrm{C}$. This value was calculated from the temperature dependence of $\Lambda_{0}$ obtained from limiting molar conductivities and transport numbers for $\mathrm{LiCl}$ and $\mathrm{KBr} .{ }^{21}$

Acknowledgements. The author thanks Mrs. Margareta Ögren for technical assistance and the Swedish Natural Science Research Council for financial support.

\section{REFERENCES}

1. Holmgren, A. and Beronius, P. Acta Chem. Scand. 26 (1972) 3881.

2. Holmgren, A. Acta Chem. Scand. A 31 (1977) 539.

3. Nilsson, A.-M. and Beronius, P. Z. Phys. Chem. Frankfurt am Main 79 (1972) 83.

4. Daggett, H. M., Bair, E. J. and Kraus, C. A. J. Am. Chem. Soc. 73 (1951) 799.

5. Hawes, J. L. and Kay, R. L. J. Phys. Chem. 69 (1965) 2420.

6. Kay, R. L., Hales, B. J. and Cunningham, G. P. J. Phys. Chem. 71 (1967) 3925.

7. Fuoss, R. M. and Hsia, K.-L. Proc. Natl. Acad. Sci. U.S.A. 57 (1967) 1550.

8. Fuoss, R. M. and Hsia, K.-L. Proc. Natl. Acad. Sci. U.S.A. 58 (1968) 1818.

9. Fernández-Prini, R. Trans. Faraday Soc. 65 (1969) 3311.

10. Fuoss, R. M. and Accascina, F. Electrolytic Conductance, Interscience, New York 1959.

11. Justice, J.-C. Electrochim. Acta 16 (1971) 701.

12. Barthel, J., Justice, J.-C. and Wachter, R. Z. Phys. Chem. Frankfurt am Main 84 (1973) 100.

13. Beronius, P. Acta Chem. Scand. A 28 (1974) 77.

14. Beronius, P. Acta Chem. Scand. A 30 (1976) 115. 